\title{
Hydraulic performance and iron removal in wetlands and lagoons treating ferruginous coal mine waters
}

\begin{abstract}
A study of hydraulic residence time has been conducted for several UK Coal Authority mine water treatment systems to evaluate the impact of residence time on the overall hydraulic performance and iron removal within the systems. A series of tracer tests were conducted within the Coal Authority mine water treatment wetlands and lagoons to measure actual hydraulic residence time. The tracer residence time distributions (RTDs) were analysed based on a tanks-in-series (TIS) model to yield the mean residence time and corresponding hydraulic characteristics of the systems. The relationship between iron retention and residence time was tested against a first-order removal model. The mean hydraulic efficiency is $69 \%$ for the wetlands compared to $24 \%$ for the lagoons, mainly attributable to comparatively greater volumetric efficiency within the wetland systems. The mean number of TIS, $n$, is 3.9 for the wetlands and 2.1 for the lagoons, illustrating considerably different flow patterns between wetlands and lagoons. There is also a notable difference of treatment efficiency for iron; mean of $81 \%$ and $47 \%$ for wetlands and lagoons, respectively. Generally, it appears that system hydraulic efficiency (derived from the principle of TIS model) corresponds with iron retention in the treatment systems.
\end{abstract}

Keyword: Ferruginous mine water; Hydraulic efficiency; Residence time; Settlement lagoon; Wetland; Tanks-in-series 